\title{
The influence of surface treatment on the implant roughness pattern
}

\author{
Marcio Borges ROSA ${ }^{1}$, Tomas ALBREKTSSON², Carlos Eduardo FRANCISCHONE ${ }^{3}$, Humberto Osvaldo SCHWARTZ \\ FILHO $^{4}$, Ann WENNERBERG 5
}

\begin{abstract}
1- DDS, PhD student, Division of Implantology, Department of Post-Graduation, School of Dentistry, São Leopoldo Mandic University, Campinas, SP, Brazil. 2- MD, PhD, ODhc Professor and Head, Department of Biomaterials, Gothenburg University, Gothenburg, Sweden.

3- DDS, MS, PhD, Professor and Head, Department of Post-Graduation, Division of Implantology, School of Dentistry, São Leopoldo Mandic University, Campinas, SP, Brazil.

4- DDS, MS, PhD, Department of Post-Graduation, Division of Implantology, School of Dentistry, University of Santo Amaro-UNISA, São Paulo, SP, Brazil. 5- LDS, PhD, Professor and Head, Department of Prosthodontics, Malmö University, Malmö, Sweden.
\end{abstract}

Corresponding address: Marcio Borges Rosa - Av. do Contorno 4849, $4^{\circ}$ andar - 30110-035 - Belo Horizonte - MG - Phone: (31) 3284-2020 - e-mail: marcio@implantare.com.br

Received: March 30, 2012 - Modification: July 18, 2012 - Accepted: August 20, 2012

\section{ABSTRACT}

\begin{abstract}
$\Delta \mathrm{n}$ important parameter for the clinical success of dental implants is the formation of direct contact between the implant and surrounding bone, whose quality is directly influenced by the implant surface roughness. A screw-shaped design and a surface with an average roughness of Sa of 1-2 $\mu \mathrm{m}$ showed a better result. The combination of blasting and etching has been a commonly used surface treatment technique. The versatility of this type of treatment allows for a wide variation in the procedures in order to obtain the desired roughness. Objectives: To compare the roughness values and morphological characteristics of 04 brands of implants, using the same type of surface treatment. In addition, to compare the results among brands, in order to assess whether the type of treatment determines the values and the characteristics of implant surface roughness. Material and methods: Three implants were purchased directly from each selected company in the market, i.e., 03 Brazilian companies (Biomet 3i of Brazil, Neodent and Titaniumfix) and 01 Korean company (Oneplant). The quantitative or numerical characterization of the roughness was performed using an interferometer. The qualitative analysis of the surface topography obtained with the treatment was analyzed using scanning electron microscopy images. Results: The evaluated implants showed a significant variation in roughness values: Sa for Oneplant was $1.01 \mu \mathrm{m}$; Titaniumfix reached $0.90 \mu \mathrm{m}$; implants from Neodent 0.67 $\mu \mathrm{m}$, and Biomet 3i of Brazil $0.53 \mu \mathrm{m}$. Moreover, the SEM images showed very different patterns for the surfaces examined. Conclusions: The surface treatment alone is not able to determine the roughness values and characteristics.
\end{abstract}

Key words: Surface treatments. Blasting. Acid etched. Dental implants. Osseointegration.

\section{INTRODUCTION}

Since the discovery of osseointegration by Brånemark, the placement of titanium implants has been established as the treatment of choice for replacing missing teeth, thereby improving the patients' quality of life ${ }^{13,18}$.

An important parameter for the clinical success of dental implants is the formation of direct contact between the implant and surrounding bone ${ }^{14}$. The quality of the bone-implant interface is directly influenced by the implant surface roughness ${ }^{1,9,10,23-25}$ which, since the early 1980 s, has been identified as one of the six factors that are particularly important for incorporating the implant into the bone ${ }^{1}$.

Both morphology and surface roughness influence cell proliferation and differentiation, extracellular matrix synthesis, local production factors, and even cell shape ${ }^{4,10}$. Furthermore, the shape of the cell regulates its growth, gene expression, protein secretion, differentiation, and apoptosis ${ }^{7}$. Therefore, osteoblast adherence on implant surfaces is not sufficient for achieving osseointegration, much less for improving it, but it is necessary, particularly 
to enable the cell to receive the signals to induce its proliferation ${ }^{10}$. In addition, roughness not only facilitates the retention of osteogenic cells, but also allows them to migrate to the implant surface by osseoconductivity ${ }^{6}$. Faster and stronger bone formation provides greater stability during the repair process, allowing for even faster implant loading ${ }^{23-25}$. Oral implant surfaces have structures that are measurable on a macrometric scale in millimeters $(\mathrm{mm})$, micrometric in micrometers $(\mu \mathrm{m})$, and nanometric in nanometers $(\mathrm{nm})^{2,3,18,22-24}$. How these structures influence repair has been the subject of various publications and studies in recent years $2,7,8,11,13,17,21,24$.

Until now, certainties have been limited to the influence of implant design and surface roughness on the micrometric scale. A screw-shaped design and a surface with an average roughness of $\mathrm{S}_{\mathrm{a}}$ of 1-2 $\mu \mathrm{m}$ have shown better results ${ }^{2,10,24,25}$. Studies have shown that titanium implants with the proper roughness can improve bone-implant contact ${ }^{29}$, while also increasing the removal torque values ${ }^{21,29}$. On the other hand, increasing the surface roughness to the level of surfaces treated with plasma spray titanium, $\mathrm{S}_{\mathrm{a}}$ above $2 \mu \mathrm{m}$, elicits a prejudiced and non-reinforced bone response ${ }^{10,23-25}$.

As a result, over the past 20 years, a large number of implant systems with different surface topographies have been introduced ${ }^{19}$. Oral implants are an example of the close link between research and industry, since the laboratory findings often become clinical applications. However, any change in the implant morphology, i.e., in its design, causes changes in the topography at the micrometric level and vice versa. Likewise, chemical changes cause physical changes and vice versa ${ }^{23-25}$. There are many types of surface treatments on the market. In general, all seek to alter the previously machined surface roughness, increasing it to levels considered optimal. A combination of blasting, followed by acid etching, has been a technique commonly used for surface treatment in recent years ${ }^{24}$. The main reason for the combination of methods is that hypothetically, blasting reaches an optimal roughness and mechanical fixation, while acid etching smooths the peaks and can add a high frequency component to the implant surface, with a potential importance for protein adherence, which is considered important during the early bone healing process ${ }^{24}$.

The surface characteristics obtained with blasting deformation depend on the type of particle used, its hardness, size, and impact velocity. The blasting process, usually performed with titanium $\left(\mathrm{TiO}_{2}\right)$ or alumina $\left(\mathrm{Al}_{2} \mathrm{O}_{3}\right)$ particles, allows for good control of the size of the resulting micro cavities. Some remaining particles may however, become embedded and contaminate the implant surface ${ }^{10}$.
Acid etching removes a few atomic layers from the deformed surface, part of the residual surface stress, and reduces the possibility of surface contamination by particles left over from the blasting process, because it also acts in cleaning the surface. These processes create micro cavities overlapping the pre-blasted rough surface.

Each manufacturer has its own method of acid etching with regard to temperature, concentration of acids, and exposure time. In general, there is dual acid etching, which is carried out by first immersing the implants in solutions of $\mathrm{HCl}+\mathrm{H}_{2} \mathrm{SO}_{4}$, $\mathrm{HNO}_{3}+\mathrm{HF}$, or $\mathrm{HNO}_{3}$. Thereafter, the implant is again immersed in an aqueous solution of $\mathrm{HNO}_{3}$ to stabilize the titanium oxide layer ${ }^{10,24}$.

The versatility of this type of treatment allows for a wide variation in the procedures to obtain the desired roughness. On the other hand, this characteristic can produce significantly different surfaces. Consequently, it is very important to characterize the surfaces to obtain the values envisioned by the proposed treatments. According to Wennerberg and Albrektsson ${ }^{23}$ (2000), a light interferometer is a safe and effective way to measure the roughness of screw-shaped implants.

This aim of this study was to characterize the surfaces, by means of using a light interferometer and scanning electron microscopy (SEM), of implants from four companies: 3 Brazilian and 1 Korean, which use blasting and acid etching treatments. The results were compared among the 4 companies.

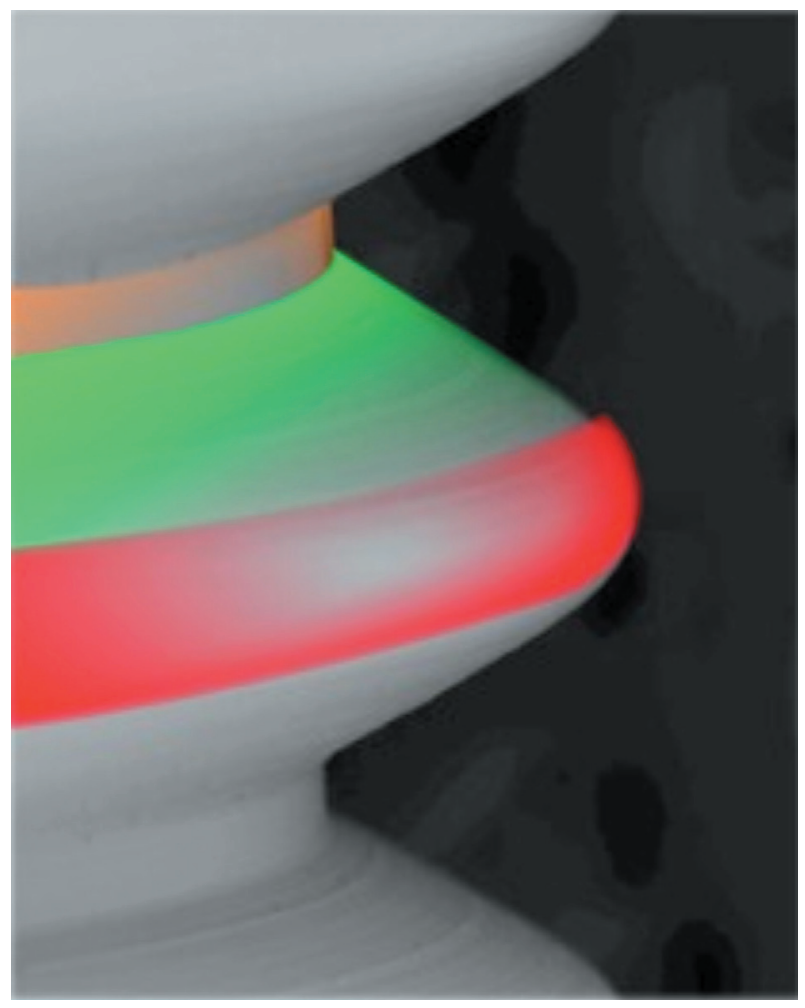

Figure 1- Red: top; green: flank; orange: valley 


\section{MATERIAL AND METHODS}

In accordance with this study design, three implants from each company would be analyzed ${ }^{16}$. Therefore, 03 implants were purchased from each of the following 3 Brazilian companies, namely Biomet 3i of Brazil (São Paulo, SP, Brazil); Neodent (Curitiba, PR, Brazil) and Titaniumfix (São José dos Campos, SP, Brazil); and 01 implant from the Korean Oneplant Company (Seoul, Korea).
The implant surfaces were evaluated using a light interferometer (MicroXAM ${ }^{\mathrm{TM}}$, Phaseshift, Tucson, AZ, USA), which, according to Wennerberg and Albrektsson ${ }^{23}$ (2000) is recommended for evaluating the roughness of implants with threads at the micrometer level. A 50X magnification and 0.62 zoom were used, and the measured area was $264 \times 200 \mu \mathrm{m}$. The mean height of the measurements varied between $80 \mu \mathrm{m}$ and $100 \mu \mathrm{m}$. The maximum resolution of this technique is $0.30 \mu \mathrm{m}$ horizontally

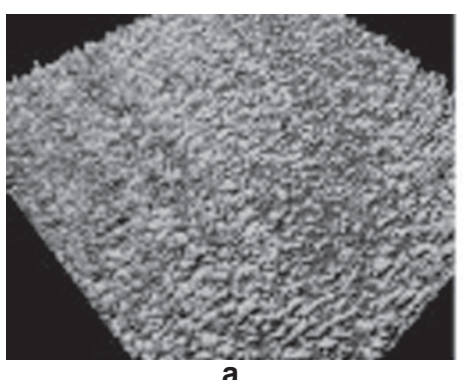

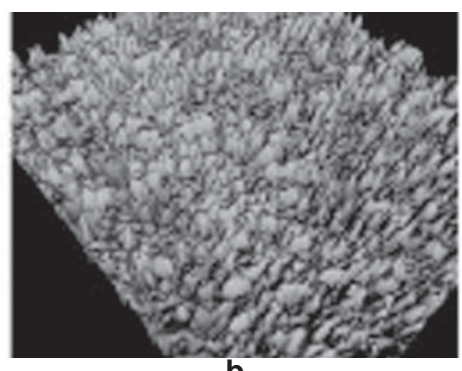

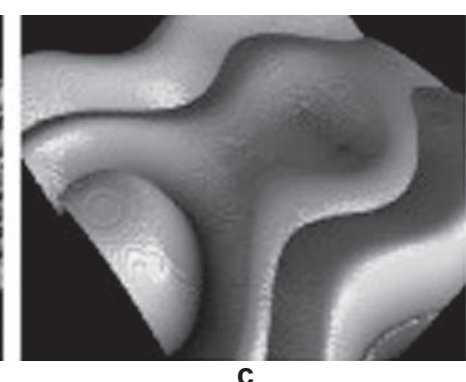

Figure 2- $a, b$ and $c$ : Filter sequence in which the undulations and shapes have been removed Note: a: Nanotite original; b: Nanotite 50X50 um Gaussian filter; c: Nanotite 50X50 $\mu \mathrm{m}$ Gaussian filter low pass ${ }^{18}$

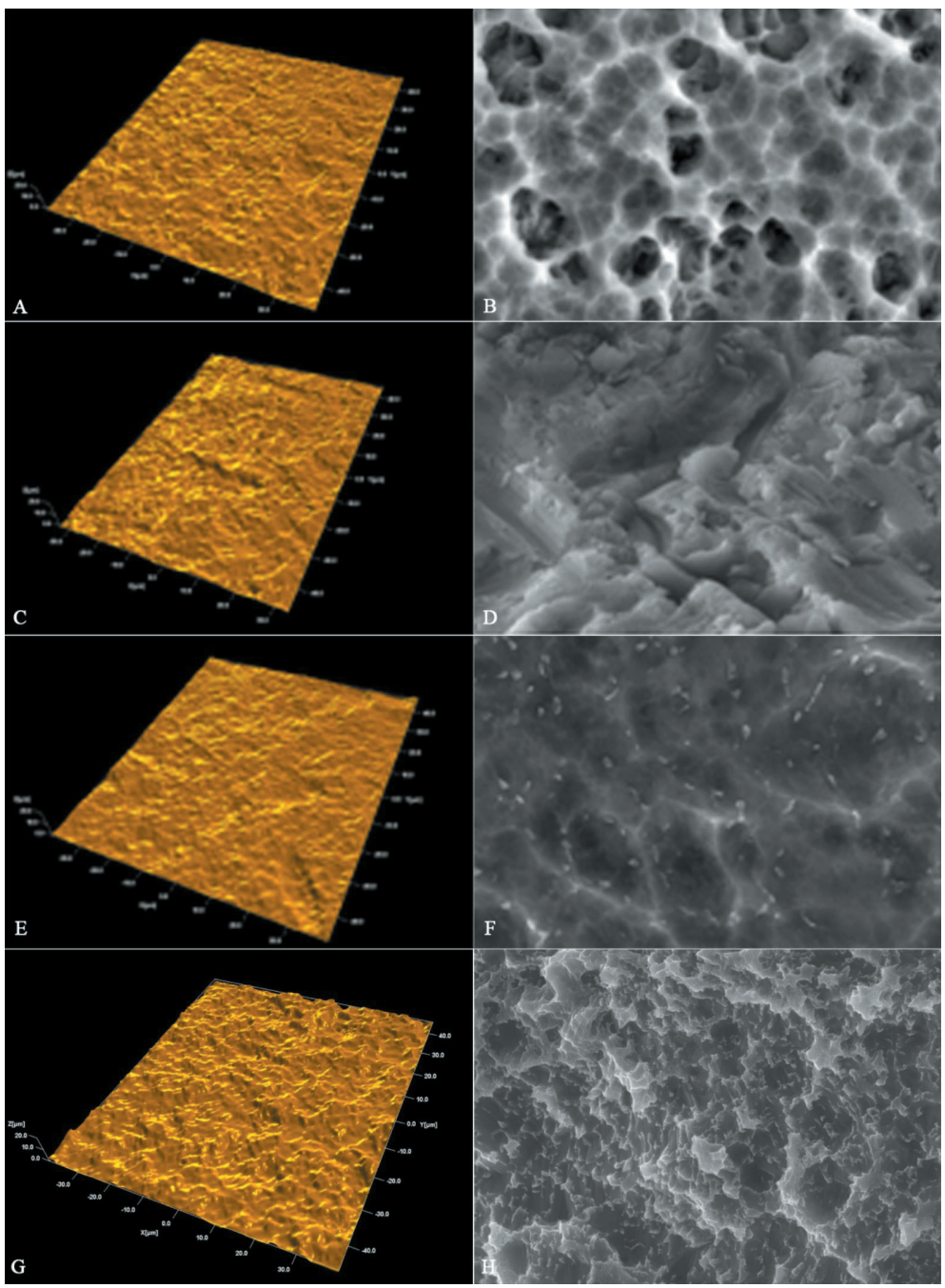

Figure 3- Interferometer images (left) and scanning electron microscopy (SEM) images 3,000X magnification (right). Note: A and B Neodent; C and D Titaniumfix; E and F 3i Biomet; $G$ and H Oneplant 
Table 1- Numerical description of the surface at a micrometer level

\begin{tabular}{lccc}
\hline & Sa $\boldsymbol{\mu m}$ & Sds $/ \mathbf{m m}^{2}$ & Sdr\% \\
\hline Oneplant & $1.01 \pm 0.20$ & $168,931 \pm 21,201$ & $73.20 \pm 37.28$ \\
Titaniumfix & $0.90 \pm 0.23$ & $164.673 \pm 10,265$ & $57.08 \pm 27.10$ \\
Neodent EX & $0.67 \pm 0.16$ & $155.725 \pm 15,727$ & $52.33 \pm 48.12$ \\
3i Bonelike CM & $0.53 \pm 0.12$ & $174.539 \pm 30,456$ & $40.20 \pm 41.56$ \\
\hline
\end{tabular}

and $0.05 \mu \mathrm{m}$ vertically.

To evaluate an implant surface, three measurements are taken in different areas, i.e., the tops, valleys, and flanks of the threads (Figure 1) totaling nine measurements for each unit. In addition, a minimum of three samples were evaluated for each implant ${ }^{16}$.

The undulations from the machining process and the shape are considered separately to adequately describe the roughness obtained with the treatment. A standard filtering process, with a $50 \times 50 \mu \mathrm{m}$ Gaussian filter was used to make the separation and evaluate the micrometric roughness (Figure 2). Surfascan software (Somicronic Instrument, Lyon, France) was used for this purpose, which also provides visual images and numerical descriptions.

The following parameters were used for the numerical description of the surface topography, which should preferably be in 3D:

$\mathrm{S}_{\mathrm{a}}$ : represented the arithmetic mean of the roughness area from the mean plane.

$\mathrm{S}_{\mathrm{ds}}$ : represented the density, i.e., the number of peaks per unit of area.

$\mathrm{S}_{\mathrm{dr}}$ : hybrid parameter that represented the ratio between the developed surface area and a flat reference area.

According to Albrektsson and Wennerberg 2 (2004) implants can be divided into four different categories, depending on the surface roughness measured by the value of $S_{a}$ : smooth $\left(S_{a}<0.5\right.$ $\mu \mathrm{m})$; minimally rough ( $\mathrm{S}_{\mathrm{a}}$ between 0.5-1.0 $\left.\mu \mathrm{m}\right)$, moderately rough ( $S_{a}$ between 1.0-2.0 $\left.\mu \mathrm{m}\right)$; rough $\left(\mathrm{S}_{\mathrm{a}}>2.0 \mu \mathrm{m}\right)$.

Images were also captured by scanning electron microscopy on the top, flank and valley of the threads, with magnifications at 65X, 350X, 1,000X, 3.000X and 5.000X. The purpose of these images was to allow a qualitative analysis of the changes obtained by the surface treatment, as well as to visualize the roughness characteristics and check the maintenance of the standard throughout the entire implant body.

\section{Statistical evaluation}

The implants were evaluated for significant differences in surface topography at the micrometric level. The statistical analyses were performed with the software GraphPad Prism 5.0 (GraphPad Software, San Diego, CA, USA). The data was analyzed by one-way ANOVA (Kruskall-Wallis test) with the significance level set at $p<0.05$, and the application of the Dunn's multiple comparisons test.

\section{RESULTS}

The evaluated implants showed a significant variation in roughness values: Sa for Oneplant was $1.01 \mu \mathrm{m}$; Titaniumfix reached $0.90 \mu \mathrm{m}$; implants from Neodent $0.67 \mu \mathrm{m}$, and Biomet $3 \mathrm{i}$ of Brazil $0.53 \mu \mathrm{m}$. Moreover, the SEM images showed very different patterns for the surfaces examined (Table 1 ).

Figure 3 shows the interferometer and SEM images for the implants in this group:

\section{DISCUSSION}

When implants first began to be manufactured in developing countries, such as Brazil and Korea, the majority of the companies adopted models and surface treatments of well-known implants. Since then, no independent assessment has been made of the quality of the implant surfaces, by means of characterizing the roughness obtained, and their clinical performance.

Among the evaluated parameters, the most important are as follows: $S_{a}$, which represent the arithmetic mean, in 3D, for the height of the peaks and valleys of surface roughness; $S_{d s}$, which represents the density of peaks per unit area; and finally, $\mathrm{S}_{\mathrm{dr}}$, which is the intersection of the first two parameters and represents the surface enlargement ${ }^{2,3,12,23}$. The analysis of these factors, and prior knowledge of their influence on the repair process, makes it easier to signal the behavior of a given surface. There is strong scientific evidence about the importance of $\mathrm{S}_{\mathrm{a}}$ in the healing process $2,10,25,29$.

The type of titanium used needs to be added to these variables because its hardness directly affects the roughness obtained with the treatment. In other words, the same treatment can produce different roughness patterns in different grades of titanium ${ }^{10,23}$.

For this group of implants, with the same type of treatment - blasting and acid etching - different results were found. The Oneplant, from Korea showed a $\mathrm{S}_{\mathrm{a}}$ value of $1.01 \mu \mathrm{m}$. All of the Brazilian 
implants presented $S_{a}$ values of less than 1.0 $\mu \mathrm{m}$, with the Titaniumfix reaching $0.90 \mu \mathrm{m}$, while those from Neodent presented a mean of $0.67 \mu \mathrm{m}$. Moreover, the Bonelike implants from Biomet $3 i$ of Brazil, which uses titanium alloy $\left(\mathrm{Ti}_{6} \mathrm{Al}_{4} \mathrm{~V}\right)$, presented $\mathrm{S}_{\mathrm{a}}$ values of only $0.53 \mu \mathrm{m}$. In this particular case, the influence of the titanium alloy hardness on the low roughness should be highlighted, irrespective of which treatment would be appropriate for the materials to produce the desired roughness, and not the opposite.

When evaluating the $S_{d r}$ to compare the surface enlargement, different values were also found: Oneplant had an $\mathrm{S}_{\mathrm{dr}}$ value of $73.20 \%$; while Titaniumfix showed $57.08 \%$; Neodent a $\mathrm{S}_{\mathrm{dr}}$ value of $52.33 \%$; and Bonelike CM, a $S_{d r}$ value of $40.20 \%$, bearing in mind that an $\mathrm{S}_{\mathrm{dr}}$ value of about $50 \%$ promotes strong bone formation ${ }^{26-28}$.

For comparison, the SLA implants from Straumann, with the same type of treatment, an extensive scientific documentation and good clinical performance have shown a $S_{a}$ value of $1.53 \mu \mathrm{m}$ and a $S_{d r}$ value of $74.52 \%$.

The long-term clinical results obtained with minimally or moderately rough implants have been shown to be very similar under normal conditions ${ }^{5}$. Moreover, when placed under adverse conditions, such as in bone grafts and type IV bone or for short implants, among others, comparative studies have shown a significant superiority of the implants with a moderately rough surface ${ }^{12,14,15}$.

Thus, using an implant without knowing its real roughness, the bone repair can be weaker than expected, which is highly undesirable, especially in critical cases, where more is expected of the surface properties of the implants.

In the literature, the surface topography of blasted and etched surfaces varies greatly because of the different measuring equipment and evaluation techniques, but mainly because the blasting and etching procedures may differ as well. In blasting, the types of particles used, along with the size and impact velocity, are directly responsible for the results. In acid etching, the type of acid, exposure time, and temperature are essential factors for surface characterization ${ }^{10}$. However, in the vast majority of studies, blasted and etched implants are moderately rough, between 1.0-2.0 $\mu \mathrm{m}$, which is considered ideal and shows better results ${ }^{2,10,24,25}$.

When analyzing the SEM images, it is quite clear how the same type of treatment may lead to surfaces with very different characteristics, and therefore, the need for clinical studies that prove the efficiency of each surface obtained, must be reinforced.

Further clinical studies are needed to show the factors that these differences may really represent. However, similar surface treatments do not necessarily lead to the same results. According to Wennerberg and Albrektsson ${ }^{24,25}$ (2009, 2010) even the roughness of a machined surface, as well as blasted, acid etched and anodized surfaces, may vary considerably. They also point out that many studies and companies leave out the surface topographic characterization in the false belief that their treatment alone will determine the roughness of this surface ${ }^{24}$.

When the surface topography is altered, its chemical and/or physical characteristics can change at the same time, even accidentally ${ }^{24}$. Often, there are no short, medium, and long-term studies to evaluate the effects of these changes on the repair processes and longevity of implant osseointegration. This occurs mainly in implants, such as those from Brazilian companies that use surface treatments established by other companies, but do not conduct clinical studies to evaluate their clinical performance. It is not practicable to endorse the results of other implants only because they have the same type of surface treatment.

\section{CONCLUSION}

The results, with a significant variation in roughness values among the implants with the same type of surface treatment showed that the characterization of the surface of each implant is very important for a real evaluation of the obtained results.

Therefore, even if established treatments are used on the surface of these implants, it is very important that each company conducts its own laboratory and clinical experiments to validate them.

\section{REFERENCES}

1- Albrektsson T, Brånemark PI, Hansson HA, Lindström J. Osseointegrated titanium implants. Requirements for ensuring a long-lasting, direct bone-to-implant anchorage in man. Acta Orthop Scand. 1981;52:155-70.

2- Albrektsson T, Wennerberg A. Oral implant surfaces: part 1 - review focusing on topographic and chemical properties of different surfaces and in vivo responses to them. Int J Prosthodont. 2004;17:536-43.

3- Albrektsson T, Wennerberg A. Oral implant surfaces: part 2 review focusing on clinical knowledge of different surfaces. Int J Prosthodont. 2004;17:544-64.

4- Anselme K, Bigerelle M. Topography effects of pure titanium substrates on human osteoblast long-term adhesion. Acta Biomater. 2005; 1:211-22.

5- Balshe AA, Assad DA, Eckert SE, Koka S, Weaver AL. A retrospective study of the survival of smooth- and rough-surface dental implants. Int J Oral Maxillofacial Implants. 2009;24:1113-8. 6- Braceras I, De Maeztu MA, Alava JI, Gay-Escoda C. In vivo lowdensity bone opposition on different implant surface materials. Int J Oral Maxillofac Surg. 2009;38:274-8. 
7- Brunette MD. Principles of cell behaviour on titanium surfaces and their application to implanted devices. In: Brunette DM, Tengvall $\mathrm{P}$, Textor $\mathrm{M}$, Thomsen $\mathrm{P}$, editors. Titanium in Medicine. Berlin: Spinger Verlag; 2001. p. 485-512.

8- Chang PC, Lang NP, Giannobile WV. Evaluation of functional dynamics during osseointegration and regeneration associated with oral implants. Clin Oral Implants Res. 2010;21:1-12.

9- Cooper LF. A role for surface topography in creating and maintaining bone at titanium endosseous implants. J Prosthet Dent. 2000;84:522-34.

10- Elias CN, Meirelles L. Improving osseointegration of dental implants. Expert Rev Med Devices. 2010;7:241-56.

11- Elias CN, Oshida Y, Lima JH, Muller CA. Relationship between surface properties (roughness, wettability and morphology) of titanium and dental implant removal torque. J Mech Behav Biomed Mater. 2008;1:234-42.

12- Friberg B, Jemt T. Rehabilitation of edentulous mandibles by means of five TiUnite implants after one-stage surgery: a 1-year retrospective study of 90 patients. Clin Implant Dent Relat Res. 2008;10:47-54.

13- Mendonça G, Mendonça DB, Aragão FJ, Cooper LF. Advancing dental implant surface technology - from micron- to nanotopography. Biomaterials. 2008;29:3822-35.

14- Pinholt EM. Brånemark and ITI dental implants in the human bone-grafted maxilla: a comparative evaluation. Clin Oral Implants Res. 2003;14(5):584-92.

15- Rocci A, Martignoni M, Gottlow J. Immediate loading of Brånemark System TiUnite and machined-surface implants in the posterior mandible: a randomized open-ended clinical trial. Clin Implant Dent Relat Res. 2003;5(Suppl 1):57-63.

16- Rosa MB, Albrektsson T, Francischone CE, Schwartz Filho $\mathrm{HO}$, Wennerberg A. Micrometric characterization of the implant surfaces from the five largest companies in Brazil, the second largest worldwide implant market. Int J Oral Maxillofac Implants. In press 2012.

17- Shalabi MM, Gortemaker A, Van't Hof MA, Jansen JA, Creugers $\mathrm{NH}$. Implant surface roughness and bone healing: a systematic review. J Dent Res. 2006;85:496-500.

18- Shalabi MM, Wolke JG, Jansen JA. The effects of implant surface roughness and surgical technique on implant fixation in an in vitro model. Clin Oral Implants Res. 2006;17:172-8.
19- Strassburger C, Kerschbaum T, Heydecke G. Influence of implant and conventional prostheses on satisfaction and quality of life: a literature review. Part 2: qualitative analysis and evaluation of the studies. Int J Prosthodont. 2006;19:339-48.

20- Sul YT, Johansson C, Albrektsson T. Which surface properties enhance bone response to implants? Comparison of oxidized magnesium, TiUnite, and Osseotite implant surfaces. Int J Prosthodont. 2006;19:319-28.

21- Sul YT, Johansson CB, Jeong Y, Wennerberg A, Albrektsson $\mathrm{T}$. Resonance frequency and removal torque analysis of implants with turned and anodized surface oxides. Clin Oral Implants Res. $2002 ; 13(3): 252-9$.

22- Svanborg LM, Andersson M, Wennerberg A. Surface characterization of commercial oral implants on the nanometer level. J Biomed Mater Res B Appl Biomater. 2010;92:462-9.

23- Wennerberg A, Albrektsson T. Suggested guidelines for the topographic evaluation of implant surfaces. Int J Oral Maxillofac Implants. 2000;15:331-44.

24- Wennerberg A, Albrektsson T. Effects of titanium surface topography on bone integration: a systematic review. Clin Oral Implants Res. 2009;20(Suppl 4):172-84.

25- Wennerberg A, Albrektsson T. On implant surfaces: a review of current knowledge and opinions. Int J Oral Maxillofac Implants. 2010;25:63-74.

26- Wennerberg A, Albrektsson T, Andersson B. Bone tissue response to commercially pure titanium implants blasted with fine and coarse particles of aluminum oxide. Int J Oral Maxillofac Implants. 1996;11:38-45.

27- Wennerberg A, Albrektsson T, Andersson B, Krol J]. A histomorphometric and removal torque study of screw-shaped titanium implants with three different surface topographies. Clin Oral Implants Res. 1995;6:24-30.

28- Wennerberg A, Albrektsson T, Johansson C, Andersson B. Experimental study of turned and grit-blasted screw-shaped implants with special emphasis on effects of blasting material and surface topography. Biomaterials. 1996;17:15-22.

29- Wennerberg A, Ektessabi A, Albrektsson T, Johansson C, Andersson B. A 1-year follow-up of implants of differing surface roughness placed in rabbit bone. Int J Oral Maxillofac Implants. 1997; 12:486-94. 